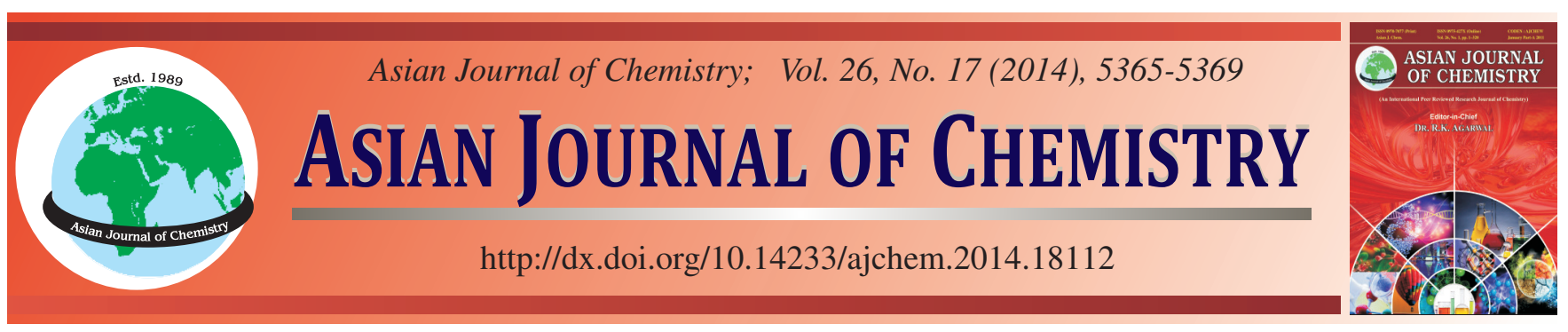

\title{
Thermodynamic and Kinetic Characteristics of Nitrogen Hydrates Respond to Thermo-Analytical Technique $\dagger$
}

\author{
Qiang Chen", Changling Liu and Yuguang Ye
}

Key Laboratory of Gas Hydrate, Ministry of Land and Resources, Qingdao, P.R. China

*Corresponding author: Fax: +86 532 85765690; Tel: +86 532 85767055; E-mail: chenqiang_hds@126.com

In this study, a high pressure differential scanning calorimetry, based upon a thermo-analytical technique, was applied in order to investigate the kinetic and thermodynamic characteristics of nitrogen hydrates. The phase equilibrium conditions and the dissociation heat were determined by analyzing the endothermic heat flow curves during the hydrate dissociation process. In the nucleation stage, exothermic heat flow curves provided a lot of information about the kinetics, such as sub-cooling, nucleation time and the growth speed of hydrates crystals. In the bulk phase system, sub-cooling played an important part in the formation process of hydrates. However, other factors, such as the gas supply method, as well as the limitations that are inherent to the experimental apparatus also affected the reaction. It seems that, unlike the relatively stable behaviour in dissociation, hydrate nucleation and formation rely upon a probabilistic scheme.

Keywords: Nitrogen hydrates, High pressure differential scanning calorimetry, Kinetics, Thermodynamics, Sub-cooling.

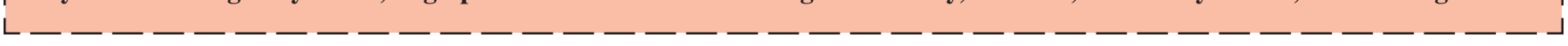

\section{INTRODUCTION}

Gas hydrates are crystalline clathrate solids that are formed from a network of hydrogen-bonded water molecules which can encapsulate suitably-sized gas molecules at high pressures and low temperatures ${ }^{1}$. For the most part, two main types of gas hydrates exist in the world: natural gas hydrates and air gas hydrates. Natural gas hydrates are primarily comprised of methane and reside throughout the globe in the sea floor and permafrost; air gas hydrates are mostly contained in the sedimentary ice of the circumpolar region. These gas hydrates, however, have both good and bad capabilities. For example, they have the potential to cause serious damage by blocking transportation along both oil and natural gas pipelines, especially as the oil and natural gas industries have been recently focusing their efforts towards deep water exploration and production $1^{2,3}$. Furthermore, there's reason to believe that the uncontrolled dissociation of gas hydrates in the ocean floor can potentially lead to global warming and climate change ${ }^{4-6}$. Alternatively, natural gas hydrates are also regarded as a potential energy resource ${ }^{7,8}$ and air hydrates could play a role in revealing paleoclimatic changes by analyzing guest species. However, determining both the kinetic and thermodynamic properties of hydrates is a necessary first step prior to carrying out in any in situ explorations ${ }^{9}$ and though they are comprised of differing compositions, the thermodynamic and kinetic characteristics of the formation and dissociation processes are similar for both the methane hydrates and the nitrogen hydrates.

Natural gas hydrate samples are difficult to acquire and require a special apparatus to properly preserve them, which makes this type of work expensive and potentially dangerous. Therefore, simulating experimental research is a successful way to by-pass these risks while still effectively investigating hydrates. The experimental studies that have been conducted thus far on the kinetic and thermodynamic characteristics of hydrate $\mathrm{s}^{10-13}$ have typically made use of traditional PVT reactors. Usually, these types of experiments require heavy instrumentation and result in a lack of precision. Differential scanning calorimetry (DSC) is a thermo-analytical technique in which the difference in the amount of heat required to increase the temperature of a sample and reference is measured as a function of temperature. Traditional DSC has been used to study hydrate properties since the 1980's, including the enthalpies of dissociation and heat capacities, etc.

Recently, a new high pressure differential scanning calorimetry (HP DSC) technique has been introduced into the hydrates research field ${ }^{14-16}$. Not only is it faster and more sensitive, but it can also measure samples under high pressures ${ }^{17-18}$. DSC was first applied to the study of hydrates by Koh et al. ${ }^{19}$, who performed experiments on a model hydrate at ambient 
pressure, quantify and compare the effect of various kinetic inhibitors. DSC coupled with X-rays diffraction was applied as a complementary technique to elucidate the complex thermal events during ice crystallization and melting ${ }^{20}$. The first application of HP DSC to gas hydrates was developed to characterize the thermodynamic stability limits of methane and natural gas hydrates in solutions of inhibitors ${ }^{21}$.

This new technology has made more precise studies possible, such as improving the precision of studies conducted on kinetic and thermodynamic properties. In this paper, HP DSC is used to analyze the characteristics associated with nitrogen hydrates formation and dissociation. With these experiments, the hydrate phase transition conditions, nucleation, crystal growth speed and dissociation enthalpies have been studied.

\section{EXPERIMENTAL}

The HP DSC equipment ( $\mu$ DSC VII) that was used in this experiment was manufactured by Setaram Inc. The pressure was controlled by a gas panel that compressed the gas to a $0.1-40 \mathrm{MPa}$ range by a piston. It can be operated at a temperature range of -45 to $120^{\circ} \mathrm{C}$ and has a resolution of $0.04 \mu \mathrm{W}$ for measuring heat flow.

The gas tight, high pressure vessels with a $0.5 \mathrm{~mL}$ capacity are designed to work up to a pressure of 400 bar. These vessels are made of Hastelloy $\mathrm{C} 276$ for corrosive fluids analysis. They are also equipped with doughnut rings coupled to an antiextrusion ring at the screwed top so as to maintain the high pressure conditions.

Before starting any scientific program, the HP DSC must be calibrated to ensure data qualification. The temperature calibrations were performed annually according to the Setaram manual with reference samples of Napthalene. After calibration, a similar procedure was applied to measure the deionized water produced in our lab. Table-1 illustrates the comparison between the NIST data and the results of the temperature and enthalpy obtained by the DSC apparatus. The measured data agreed well with the standard data.

\begin{tabular}{ccccc}
\multicolumn{5}{c}{ TABLE-1 } \\
\multicolumn{5}{c}{ DSC TEMPERATURE AND ENTHALPY DATA VALIDATION } \\
\hline Material & $\begin{array}{c}\text { NIST } \\
\text { transition } \\
\text { temp. }\left({ }^{\circ} \mathrm{C}\right)\end{array}$ & $\begin{array}{c}\text { NIST } \\
\text { enthalpy } \\
(\mathrm{J} / \mathrm{g})\end{array}$ & $\begin{array}{c}\text { DSC } \\
\text { transition } \\
\text { temp. }\left({ }^{\circ} \mathrm{C}\right)\end{array}$ & $\begin{array}{c}\text { DSC } \\
\text { enthalpy } \\
(\mathrm{J} / \mathrm{g})\end{array}$ \\
\hline $\begin{array}{c}\text { Water } \\
\text { Napthalene }\end{array}$ & 0 & 333.33 & 0.469 & 336.366 \\
& 80.23 & 147.6 & 80.312 & 148.499 \\
\hline
\end{tabular}

Procedure: The empty sample vessel was measured using an analytical balance. Then, about $30 \mu \mathrm{L}$ of distilled water was added to the vessel using a micro-volume syringe and the vessel's total mass was recorded again on the analytical balance. Doing so gives the water's total mass; this number will be used for later quantitative analysis. The whole system was then vacuumed by a mechanical pump for about $1 \mathrm{~min}$ before the high pressure gas was charged into the vessels by the gas panel.

In this study, nitrogen hydrates were synthesized in the sample vessel under different pressures as the temperature was decreased from 20 to $-40{ }^{\circ} \mathrm{C}$ with a constant cooling rate of
$0.2 \mathrm{~K} / \mathrm{min}$ controlled by the DSC. To measure the hydrates dissociation enthalpies and phase equilibrium points, the temperature was slowly raised from -40 to $20^{\circ} \mathrm{C}$ at a constant rate change of $0.05^{\circ} \mathrm{C} / \mathrm{min}$.

\section{RESULTS AND DISCUSSION}

Heat flow responds to the hydrate phase transition: The basic principle of the DSC technique is that when the sample undergoes a physical transformation or chemical reaction, either more or less heat will need to flow to it than to the reference in order to maintain both at the same temperature. One of the most important properties of the hydrate reaction is heat exchange. The formation of hydrates through the encapsulation of gas molecules by water lattices is obviously accompanied by a release of heat, typically generating 1.53.0 times more energy than freezing ice ${ }^{29}$ and conversely, the dissociation process exhibits an endothermic reaction. Therefore, it is reasonable to use the DSC technique to study hydrates. Fig. 1 illustrates the typical shape of a heat flow curve that has been acquired by HP DSC during an in situ formation and dissociation of hydrates. The reaction material contains deionized water and nitrogen gas. As clearly demonstrated, there are two exothermic peaks during the cooling and two endothermic peaks during the heating, which correspond to water freezing and melting and the hydrates' formation and dissociation. It is easy to differentiate ice from a hydrate as the melting point of ice is always near $0{ }^{\circ} \mathrm{C}$ regardless of the pressure.

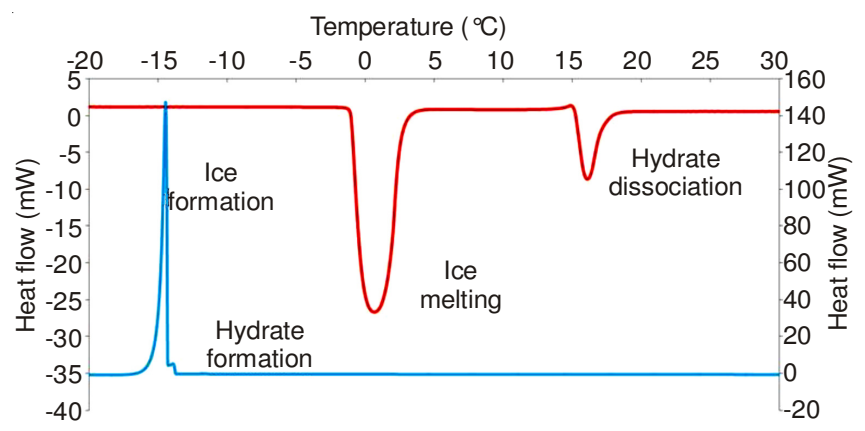

Fig. 1. Heat flow variation during cooling and heating processes

Phase equilibrium of nitrogen hydrates: After the hydrates had been synthesized in the high pressure sample vessel, a constant heating ramp was set to warm the samples. As the temperature increased to certain points, the sample would suffer some sort of physical or chemical reaction, such as a melting or dissociation with a heat exchange and consequently, there should be a corresponding peak shown on the heat flow curve. Fig. 2 shows the phase transition peaks that were obtained from heating the sample from $-40{ }^{\circ} \mathrm{C}$ to $30^{\circ} \mathrm{C}$ at $0.05 \mathrm{~K} / \mathrm{min}$ under different pressures. Two kinds of endothermic peaks can be identified: one corresponding to the ice melting and a second corresponding to hydrate dissociation. The exothermic peak located at the beginning is simply a response to the intersection of the cooling to heating process.

As shown in the Fig. 2, the hydrates' dissociation peaks are very pressure-sensitive, meaning that the hydrates need a lower temperature to remain stable if the pressure is low. In 


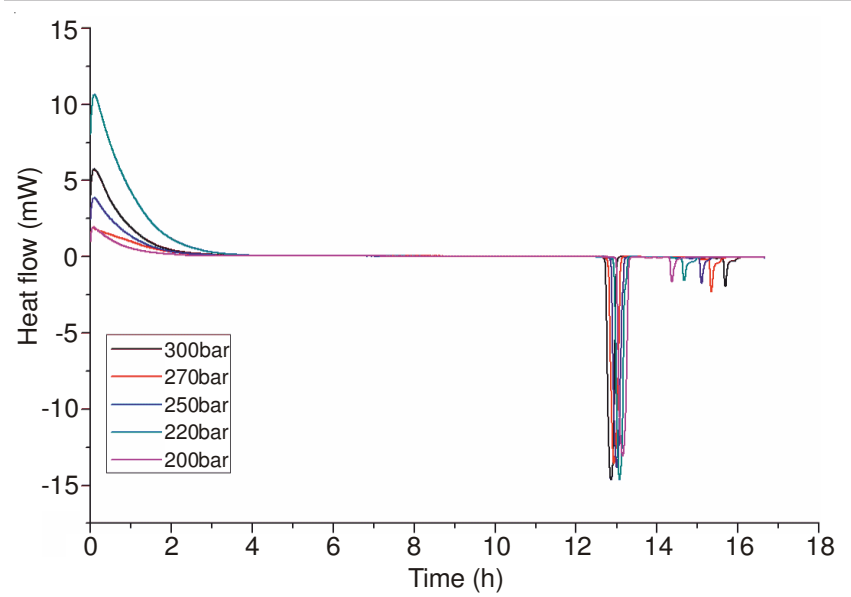

Fig. 2. Heat flow curve of nitrogen hydrates dissociation at different pressures

the DSC experiment, the ramp rate is very slow (usually 0.05 ${ }^{\circ} \mathrm{C} / \mathrm{min}$ ), which ensures there is adequate time for the phrase transition process to occur. Therefore, the temperature corresponding to the onset point of the hydrates' endothermic peak is usually considered to be the phase equilibrium point.

Fig. 3 illustrates the phase equilibrium data for the nitrogen hydrates. The data obtained by the HP DSC was compared with literature ${ }^{22,23}$ and they were found to agree well with one another. Therefore in the bulk phase, the onset point, defined as the intersection of the base line with the tangent to the linear part of the peak, can be considered an effective mark for determining hydrate phase equilibrium points.

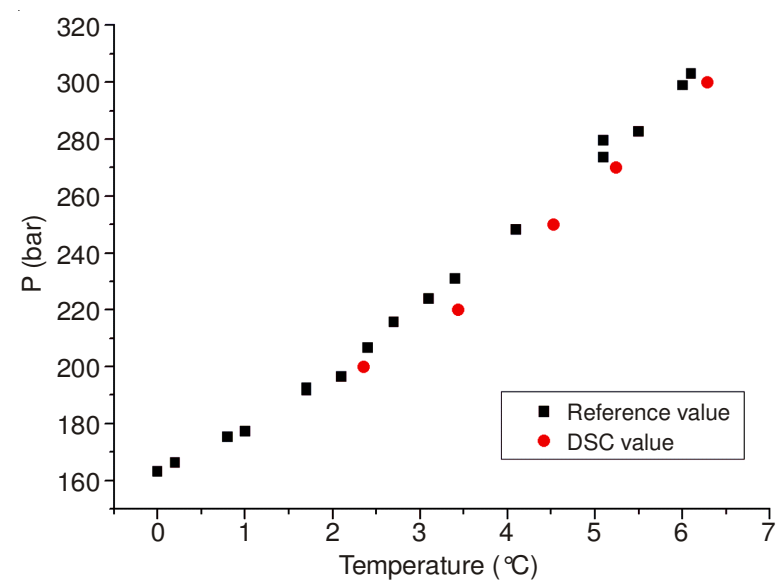

Fig. 3. Phase equilibrium point of nitrogen hydrates (Reference value: van Cleff,A., Diepen, G.A.M. ${ }^{24}$ )

Dissociation heat of nitrogen hydrates: The peak area on the heat flow curves is representative of the amount of heat during the phase transition. In these experiments, the total water added to the sample vessel $\left(\mathrm{m}_{\mathrm{t}}\right)$ is already known. By integrating the peak areas of both the ice and the hydrate, we know the total heats for the ice $\left(\mathrm{Q}_{\mathrm{i}}\right)$ and hydrate $\left(\mathrm{Q}_{\mathrm{h}}\right)$. As the heat of ice per gram can be easily measured $(336.366 \mathrm{~J} / \mathrm{g})$, the ice's mass $\left(\mathrm{m}_{\mathrm{i}}\right)$ can also be calculated. Then, the nitrogen hydrate's dissociation heat per gram $\left(\mathrm{H}_{\mathrm{h}}\right)$ can be calculated by the following equation:

$$
\mathrm{H}\left(\frac{\mathrm{J}}{\mathrm{g}}\right)=\frac{\mathrm{Q}_{\mathrm{h}}}{\left(\mathrm{m}_{\mathrm{t}}-\mathrm{m}_{\mathrm{i}}\right)}
$$

Table-2 lists the nitrogen hydrates' dissociation heats. The results indicate that the nitrogen hydrates' dissociation heats are slightly larger than those of the ice, but they do not significantly change under different pressures. The average dissociation heat value is $369.158 \mathrm{~J} / \mathrm{g}$.

\section{Kinetics properties of hydrates formation}

Nucleation study in water-gas-hydrate system: Nucleation is the first step of hydrate formation. Though there is a certain phase equilibrium temperature for each pressure, further conditions need to be met before hydrate synthesis will occur. Nucleation not only relies on a probabilistic scheme, but it also has to overcome a potential barrier for the reaction to start. The driving force is defined as the energy needed to initiate hydrate synthesis and is usually considered to be related to sub-cooling. After simplifying, the driving force can be expressed by the following equation ${ }^{25}$ :

$$
\Delta \mathrm{u}=\Delta \mathrm{Se}(\mathrm{Te}-\mathrm{T})=\Delta \mathrm{Se} \Delta \mathrm{T}
$$

where $\Delta \mathrm{u}$ is the driving force, $\Delta \mathrm{Se}$ is the system's enthalpy change, Te is the phase equilibrium temperature, $\mathrm{T}$ is the hydrate formation temperature and $\Delta \mathrm{T}$ is sub-cooling.

According to this equation, greater sub-cooling provides a larger driving force. Fig. 4 shows that during the DSC cooling stage, hydrate formation occurs at a temperature that is much lower than the equilibrium. The largest sub-cooling is about $18{ }^{\circ} \mathrm{C}$ while the smallest one is about $6{ }^{\circ} \mathrm{C}$. However, during these experiments, the pressure did not appear to have any clear relationship with the sub-cooling. This confirmed that, although the proper conditions were met, nucleation was still a stochastic process. For example, due to the random distribution of dissolved gas in the water, the interfacial tension and the water activity were not equal throughout the whole system. Furthermore, if there was a free gas phase, it would have lead to a different fugacity on the water-gas interface and the stochastic behaviour would have been more significant in the sample vessel.

The heat signal that is recorded during the hydrate formation process perhaps represents the sum of the elementary heat releases from lots of tiny nuclei. Therefore, the time scale of the formation peak can be treated as a statistical analysis of the hydrates nucleated duration.

\begin{tabular}{cccccccc}
\multicolumn{8}{c}{ TABLE-2 } \\
\hline Dissociation (bar) & $\mathrm{m}_{\mathrm{t}}(\mathrm{mg})$ & $\mathrm{Q}_{\mathrm{i}}(\mathrm{mJ})$ & $\mathrm{m}_{\mathrm{i}}(\mathrm{mg})$ & $\mathrm{Q}_{\mathrm{h}}(\mathrm{mJ})$ & $\mathrm{m}_{\mathrm{h}}(\mathrm{mg})$ & $\mathrm{H}_{\mathrm{h}}(\mathrm{J} / \mathrm{g})$ & $\mathrm{H}_{\mathrm{avg}}(\mathrm{J} / \mathrm{g})$ \\
\hline 300 & 30.3 & 9536 & 28.35 & 700.2 & 1.949 & 359.29 & \\
270 & 30.3 & 9422 & 28.01 & 856.6 & 2.289 & 374.24 & 369.25 \\
250 & 30.3 & 9648 & 28.68 & 588.5 & 1.616 & 369.158 \\
220 & 30.3 & 9549 & 28.39 & 701.2 & 1.912 & 366.67 & 381.34 \\
200 & 30.3 & 9681 & 28.78 & 578.8 & 1.518 & \\
\hline
\end{tabular}




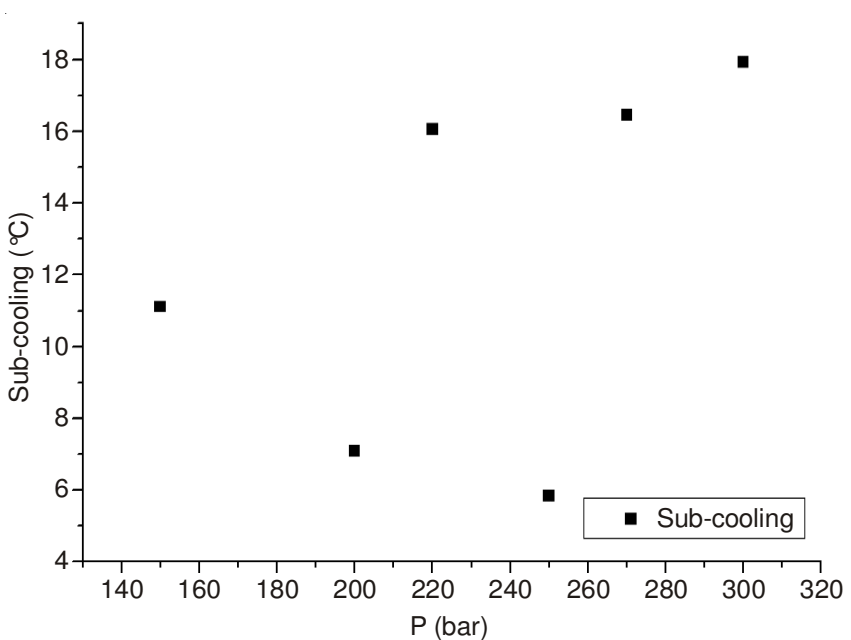

Fig. 4. Sub-cooling versus pressure during hydrate nucleation

In present experiments, there was more than one exothermic peak during the nucleation stage, which means that hydrate nuclei occurred at a different time and position. Here, the nucleation time is defined as the duration between the onset point of the first exothermic peak and the endpoint of the last one. As shown in Fig. 5, the sub-cooling degree plays an important role in controlling the nucleation time. Typically the larger the sub-cooling is, the longer the reaction time and therefore, the likelihood of hydrate synthesis increases. However, there are two abnormal values at very high sub-cooling. An analysis of the heat flow curves may help interpret these abnormities.

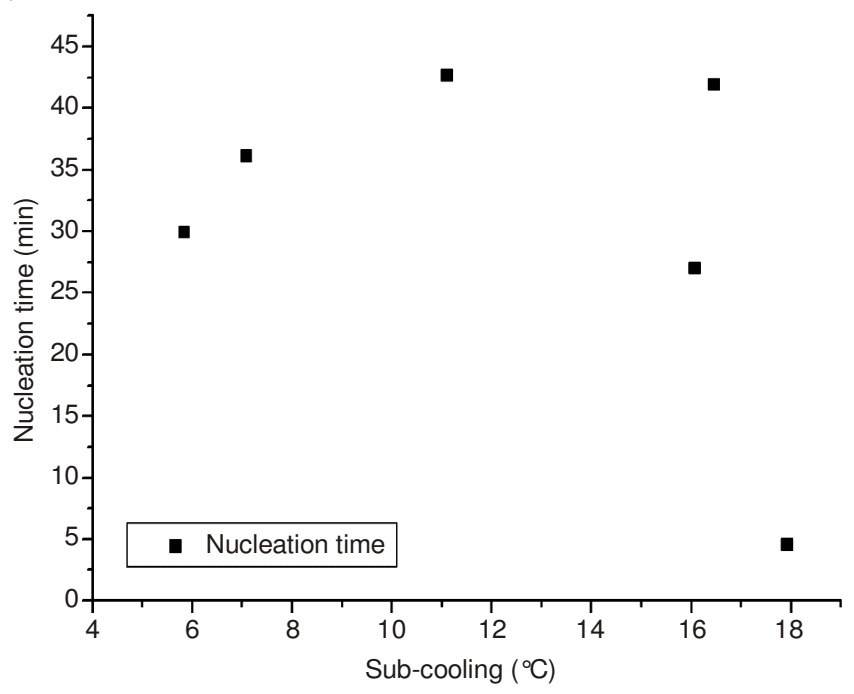

Fig. 5. Nitrogen hydrate nucleation time as a function of sub-cooling

As seen from the curve shape of 300 bar (Fig. 6), two exothermic peaks at 238 and $382 \mathrm{~mJ}$ energy, located at the beginning, suggests that the nucleation was both drastic and fast. For the 270 bar experiment (Fig. 7), although the energy was also very large, it contained more than four peaks throughout the whole process and the first peak area was not very large. This implies that the nucleation started at a normal speed and lasted a long time. Many studies ${ }^{26}$ have proven that hydrates are more likely to form at the interface between water and gas in the bulk system (Fig. 8). The sample vessel used in the

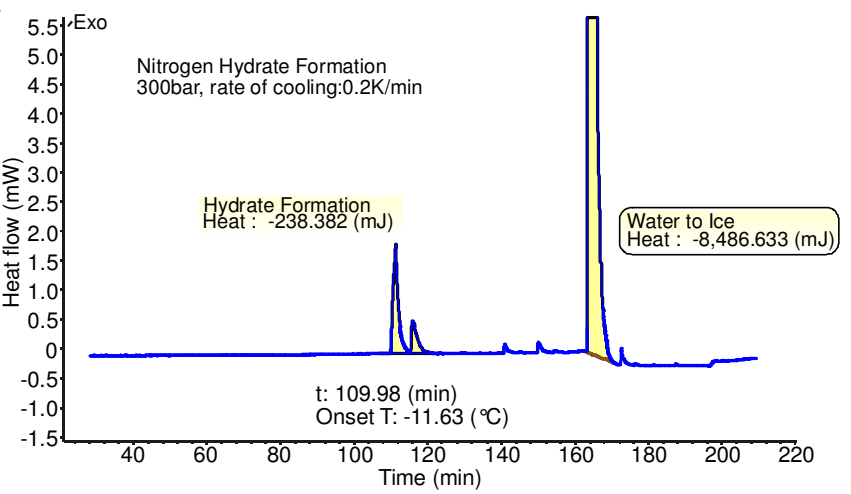

Fig. 6. Heat flow curve of hydrate formation under 300 bar with sub-cooling $17.9^{\circ} \mathrm{C}$

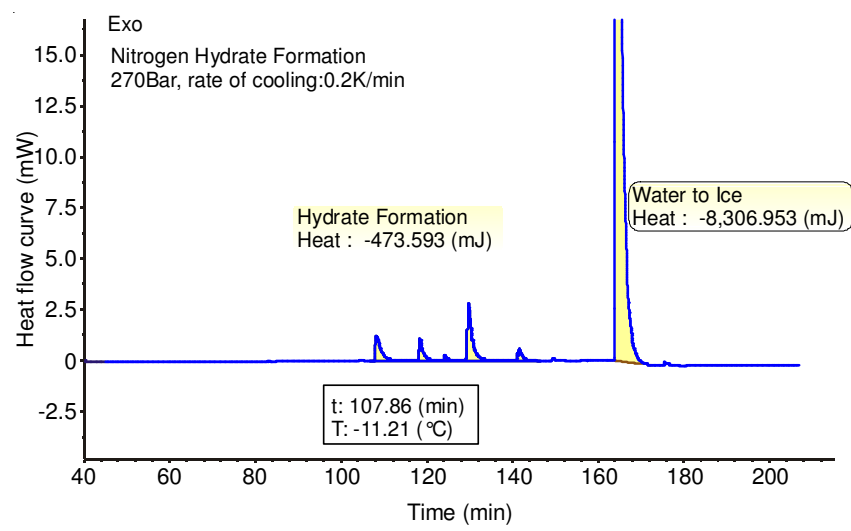

Fig. 7. Heat flow curve of hydrate formation under 270 bar with sub-cooling $16.5^{\circ} \mathrm{C}$

DSC test is a relatively small cylinder with a radius of about $4 \mathrm{~mm}$. Therefore, it was highly probable that, during the 300 bar test, a large amount of the hydrates formed at the water-gas interface and consequently blocked the gas passage way into the bulk phase, which then stopped the hydrates' continuous formation. As exhibited by the heat flow curve, there was no other obvious exothermic peak after the beginning of nucleation. In contrast, in the 270 bar test, the hydrates nucleated gently at the beginning and did not cover the whole interface, so gas was able to reach the bulk phase and continue reacting with the water molecules. Additionally, the initial nucleated crystals can act as a heterogeneous nuclei ${ }^{27}$ which promotes the hydrate formation. Correspondingly, there were four significant exothermic peaks distributed along a relatively long time scale on the heat flow curve, which was also the greatest total energy release.

Growth speed of hydrates crystal: The energy released from the hydrates' formation as a function of time can be obtained by integrating the exothermic peaks. As a series of experiments were carried out using the same bulk phase, these curves represented a semi-quantitative result of hydrate crystal growth speed (Fig. 9).

The slope of the energy curve reflected the growth speed at a certain time. The steeper the curve became, the faster the hydrates growth. As expected, the hydrate growth speed is extremely dependent upon the sub-cooling. Moreover, the total released energy also increased with sub-cooling, except for in some cases when the kinetics processes were interfered with by other factors, such as gas supply. 


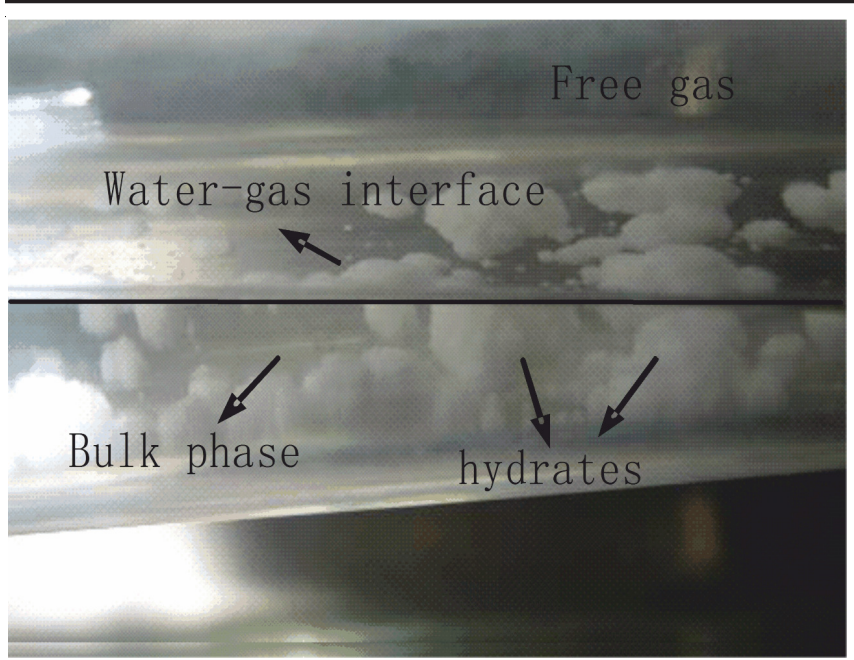

Fig. 8. Hydrates formation in water-gas-hydrates system. (Hydrates were synthesized in a transparent high pressure vessel)

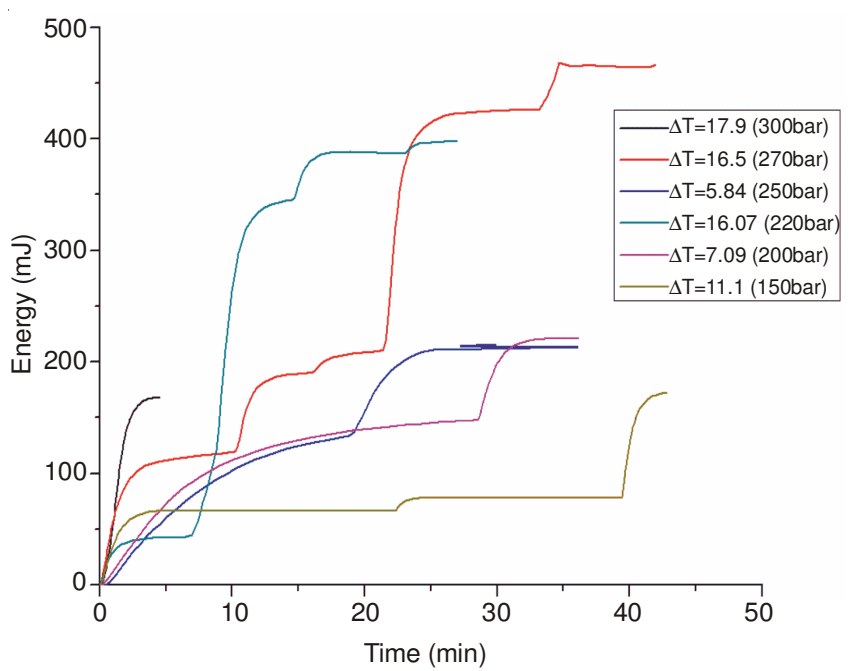

Fig. 9. Energy released of hydrates growth as a function of time

\section{Conclusion}

In this paper, an HP DSC was used to investigate the kinetic and thermodynamic characteristics of nitrogen hydrates. The HP DSC is a reliable and convenient tool ${ }^{28-30}$, especially when compared with classical PVT techniques that require larger sample volumes and are more time-consuming.

Any heat that is during a hydrates reaction can be sensitively detected by the DSC and then reflected as a heat flow curve in response to time or to a furnace temperature. There were exothermic or endothermic peaks during the system cooling or heating process, corresponding to the water phase transition and the hydrates reaction. Because of the stochastic behaviour of the hydrates nucleation, there may be more than one hydrates exothermic peaks that appeared during the system cooling. Therefore, they were suitable for studying hydrate kinetics. In contrast, a hydrates dissociation peak was always stable at the phase equilibrium condition and can be conveniently used to analyze the thermodynamics properties.

In this study, the nitrogen hydrates phase equilibrium points from 150 to 300 bar were determined and fit very well with reference values. Dissociation heats were also calculated by integrating the endothermic peak area and showed relative stable data as a function of pressure.

The nucleation duration and the hydrate growth speed were related to the total peaks' width and the slope of the energy increasing curve. As expected, sub-cooling in the bulk phase played an important role on the kinetic process of hydrates. Larger sub-cooling increased the driving force, which in turn, caused the nucleation process to be more drastic. However, the stochastic behaviour still existed due to the gas supply method and experimental apparatus.

\section{ACKNOWLEDGEMENTS}

This work was financially supported by the National Natural Science Funds (Grant No.51306096) and the Natural Science Funds of Shandong Province (Grant No. ZR2013DQ024).

\section{REFERENCES}

1. E.D. Sloan Jr. and C. Koh, Clathrate Hydrates of Natural Gases; CRC Press: Boca Raton, FL, USA, edn. 3, pp. 528-576 (2008).

2. J.S. Gudmundsson, 4th International Conference on Gas Hydrates, Yolohoma, Japan, pp. 912-915 (2002).

3. E.G. Hammerschmidt, Ind. Eng. Chem., 26, 851 (1934).

4. S.G. Hatzikiriakos and P. Englezos, Chem. Eng. Sci., 48, 3963 (1993).

5. S.G. Hatzikiriakos and P. Englezos, Offshore and Pol. Eng. J., 4, 162 (1994).

6. N. Wu, H. Zhang and S. Yang, Nat. Gas. Ind, 27, 1 (2007).

7. G. Holder, P.F. Angert, V. John and S. Yen, J. Pet. Technol., 34, 1127 (1982).

8. S.Y. Lee and G.D. Holder, Fuel Process. Technol., 71, 181 (2001).

9. M. Pooladi-Darvish, J. Pet. Technol., 56, 65 (2004).

10. Y.P. Handa and D.Y. Stupin, J. Phys. Chem., 96, 8599 (1992).

11. J.B. Klauda and S.I. Sandler, Ind. Eng. Chem. Res., 39, 3377 (2000).

12. J.B. Klauda and S.I. Sandler, Mar. Pet. Geol., 20, 459 (2003).

13. T. Uchida, T. Ebinuma and T. Ishizaki, J. Phys. Chem. B, 103, 3659 (1999).

14. Y. Handa, J. Chem. Thermodyn., 18, 891 (1986).

15. Y. Handa, J. Chem. Thermodyn., 18, 915 (1986).

16. S.P. Kang, H. Lee and B.J. Ryu, J. Chem. Thermodyn., 33, 513 (2001).

17. C. Dalmazzone, B. Herzhaft, L. Rousseau, P. Parlouer and D. Dalmazzone, SPE Annual Technical Conference and Exhibition, Denver, Colorado, USA, pp. 1980-1985 (2003).

18. A. Gupta, J. Lachance, E.D. Sloan Jr. and C.A. Koh, Chem. Eng. Sci., 63, 5848 (2008).

19. C.A. Koh, R.E. Westacott, W. Zhang, K. Hirachand, J.L. Creek and A.K. Soper, Fluid Phase Equilib., 194-197, 143 (2002).

20. B. Fouconnier, Ph.D. Thesis, University of Technology, France (2002).

21. D. Dalmazzone, M. Kharrat, V. Lachet, B. Fouconnier and D. Clausse, J. Therm. Anal. Calorim., 70, 493 (2002).

22. D. Dalmazzone, D. Clausse, C. Dalmazzone and B. Herzhaft, Am. Mineral., 89, 1183 (2004).

23. D. Dalmazzone, N. Hamed, C. Dalmazzone and L. Rousseau, J. Therm. Anal. Calorim., 85, 361 (2006).

24. A. Van Cleeff and G. Diepen, Recl. Trav. Chim. Pays Bas, 84, 1085 (1965).

25. D. Kashchiev and A. Firoozabadi, J. Cryst. Growth, 241, 220 (2002).

26. D. Huang, J. Geophys. Res., 110, 1311 (2005).

27. D. Dalmazzone, N. Hamed and C. Dalmazzone, Chem. Eng. Sci., 64, 2020 (2009).

28. S.R. Davies, K.C. Hester, J.W. Lachance, C.A. Koh and E. Dendy Sloan, Chem. Eng. Sci., 64, 370 (2009).

29. M. Kharrat and D. Dalmazzone, J. Chem. Thermodyn., 35, 1489 (2003).

30. M. Richardson, Thermochim. Acta, 300, 15 (1997). 